\title{
Deficient Knowledge on Hepatitis B Infection in Pregnant Women and Prevalence of Hepatitis B Surface Antigen Carriage in an Endemic Area: A Review
}

\author{
Oi Ka Chan, Terence T. Lao, Stephen S. H. Suen, and Tak Yeung Leung \\ Department of Obstetrics and Gynaecology, Prince of Wales Hospital, The Chinese University of Hong Kong, Shatin, \\ New Territories, Hong Kong \\ Correspondence should be addressed to Terence T. Lao, lao-tt@cuhk.edu.hk
}

Received 29 February 2012; Accepted 29 August 2012

Academic Editor: Savino Bruno

Copyright ( $) 2012$ Oi Ka Chan et al. This is an open access article distributed under the Creative Commons Attribution License, which permits unrestricted use, distribution, and reproduction in any medium, provided the original work is properly cited.

Hepatitis B infection is a major global health problem. Vertical transmission is the commonest route of spreading hepatitis B virus (HBV) in many endemic areas. In order to control such transmission in Hong Kong, neonatal immunization programme was implemented for more than two decades. A declining prevalence of HBV infection was expected. However, the prevalence remained unabated at around $10 \%$ in recent studies. We suspect that one of the explanations of this persistent high prevalence is deficient knowledge on infection with the HBV and its prevention. Our paper gives an overview of the knowledge on HBV infection among Chinese population in both high and low endemic areas and discusses the potential factors that influenced the knowledge on as well as the implication of the sources of information for HBV infection, which was not addressed in previous studies.

\section{Background}

Hepatitis B infection is a worldwide problem with over 350 million carriers [1]. Subjects with chronic hepatitis $\mathrm{B}$ virus (HBV) infection are at increased risk of hepatocellular carcinoma, cirrhosis, and chronic hepatitis $[2-$ 4]. Chronic infection with HBV is endemic in the AsiaPacific region and China. Hong Kong, as part of China, is a high-prevalence area for HBV infection according to the WHO definition, and antenatal screening for maternal infection, in the form of screening for hepatitis B surface antigen ( $\mathrm{HBs} \mathrm{Ag})$, is a standard procedure. Hong Kong is one of the first cities that introduced immunoprophylaxis to the neonates in 1983, with combined immunoglobulin and vaccine given to offspring of mothers with positive screening, and this was followed by universal vaccination to all newborn infants from $1988[5,6]$. Compliance is ensured by means of a vaccination record issued to all children, which has to be checked by teachers at primary and secondary schools (under the enforced free education system) to ensure that incompletion of any vaccination could be remedied. Furthermore, all nonimmune adult residents of Hong Kong have opportunities in obtaining vaccination from various institutions such as universities and nongovernment organizations. Good compliance with the vaccination, especially in a nationwide government-initiated public health programme as implemented in Taiwan, has resulted in a decline in the HBV carrier rate in children from $10 \%$ to $<1 \%$ and reduction in mortality from fulminant hepatitis and hepatoma in children [7, 8]. Yet in the past four decades, studies on maternal HBV infection in Hong Kong yielded the prevalence of $6.6 \%$ in 1976 [9], 7.4\% in 1983 [10], and $10.0 \%$ in 1996 [5], and which has remained unabated at around $10 \%$ in the most recent studies $[11,12]$. Therefore, the persistence of a high and apparently rising prevalence of $\mathrm{HBV}$ infection was unexpected. We suspect that one of the explanations of this persistently high prevalence is deficient knowledge on infection with the HBV, especially regarding its prevention in horizontal transmission, in the fertile female population. 


\section{Studies on Knowledge}

There are few reported studies on the knowledge of HBV infection among pregnant women, which can be taken as proxy for the fertile females among the general population. To address this issue, we have conducted a survey to examine the knowledge of HBV infection in a nonselected cohort of Chinese pregnant women attending our antenatal clinic in 2008 [13]. We found insufficient knowledge on HBV infection in various aspects which were similar to the findings in all other studies in the Chinese immigrant populations in some low endemic areas [14-20]. It is noteworthy that between $27 \%$ and $75 \%$ of the studied subjects realized that HBV infection can be a lifelong condition, and $75 \%$ and $60 \%$ of them knew that HBV infection is associated with cirrhosis and liver cancer, respectively. The findings of the aforementioned studies are summarized in Table 1.

\section{Knowledge on Vertical Transmission and Its Prevention}

3.1. Hepatitis B Neonatal Vaccination Programme. Vertical transmission of HBV from an infected mother to her infant is a major source of infection in many endemic areas $[5,10,23-$ 27]. In order to control the vertical transmission of $\mathrm{HBV}$, neonatal immunisation programmes involving the use of immunoglobulin and hepatitis B vaccine have been adopted in many countries $[28,29]$. In Hong Kong, this programme was introduced in 1983, following a prospective randomized study that had proved its efficacy $[10,30]$. From 1983 to 1988 , this programme was selective in that only neonates born to mothers with chronic HBV infection, as reflected in their positive HBsAg status, received immunoglobulin and a triple dose vaccination at the time of birth [5]. From November 1988, this programme became universal and covered all neonates born to both HBsAg positive and negative mothers as a government-initiated standard public health preventive measure, and a free vaccinations package, including that for $\mathrm{HBV}$, was provided to all newborn infants in the Government Maternal and Child Health Centres under the Department of Health [6, 31]. Nowadays, the universal immunization programme is available to the infants of all local residents. The effectiveness of universal immunization has been proven by the demonstration of reduced prevalence of childhood HBV infection and hepatocellular carcinoma in a number of endemic areas $[2,8,10,32,33]$.

Nevertheless, despite the fact that the HBV vaccine and the immunization prgramme have been introduced since the 1980s, the knowledge on perinatal transmission of HBV was quite variable among different Chinese populations, ranging from $40 \%$ to $91 \%$. Knowledge was most deficient amongst the Chinese immigrants in New York city, where only $40 \%$ of the surveyed subjects could give a correct response [19]. The results of these studies suggested that further efforts should be made in educating all Chinese women in the reproductive age group irrespective of their place of residence about vertical transmission of $\mathrm{HBV}$ infection and its prevention by the neonatal immunization programme.

\section{Knowledge on Horizontal Transmission and Its Prevention}

4.1. Horizontal Transmission. In addition to perinatal transmission, HBV can spread through sexual intercourse and contact with infected blood products through transfusion, sharing of needles and unsafe injecting equipments. Transmission through sexual contact is documented as a major route of spread of HBV in countries with low and intermediate endemicity $[24,34]$, while blood transfusion and unsafe injection are main sources of HBV transmission in many developing areas [35-37]. It has been shown that many Chinese people were not aware of the role of horizontal transmission of $\mathrm{HBV}$, especially regarding the transmission of HBV through sexual contact. Only $40-65 \%$ of surveyed subjects knew that HBV could be sexually transmitted [1322]. This deficiency in knowledge is most likely related to the oversight of not including HBV infection as one form of sexually transmitted diseases in public health promotion and educational materials, a situation that should be rectified in all places irrespective of the local prevalence of HBV infection.

However, another important aspect of deficient knowledge in Asian and Chinese communities worldwide is the risk of horizontal transmission through means others than sexual intercourse, because of the unique culture associated with the Chinese and their family settings, especially the sharing of food and eating utensils. Earlier studies have shown the presence of HBsAg in several body fluids such as saliva, semen, and urine [38-41]. Since then, HBV transmission from saliva had also been described in some studies [4245]. Furthermore, a local case of HBV transmission by human bite had been reported by a research group in recent year [46] and suggested that human bite is another route of HBV transmission. Indeed, HBV infection from saliva contact through bites or other wounds on the skin and open mouth ulcer, and as through prechewing of food from infected persons, has been reported repeatedly [46-51]. As premastication of food by the mother or grandparents before the food is fed to the infant and the shared use of chopsticks, communal eating, and sharing of utensils are still common practices in Chinese families, transmission by infected saliva could be a serious yet overlooked means of transmission, especially when the exposure by the susceptible subject would be continuous and prolonged. Indeed, even in some recent studies $[17,18,20], 11-43 \%$ of the Chinese subjects surveyed thought that HBV could not be transmitted by the sharing of eating utensils. Furthermore, HBV can survive for weeks outside the body, and it can be found on contaminated inanimate objects, such as toothbrushes and razor [52-55]. In previous studies, $41 \%$ to $86 \%$ of the subjects knew that sharing razor or toothbrush, tattooing or body piercing (37\%), eating food that has been prechewed by an infected person (69-82\%), sharing of needles (52-83\%), or exposure to blood or blood products (65-90\%) could allow HBV to spread from an infected person to susceptible individuals. In our study [13], 50.2\% of the subjects thought that HBV could be transmitted through exposure to body fluids such as saliva and urine. While horizontal transmission through the 


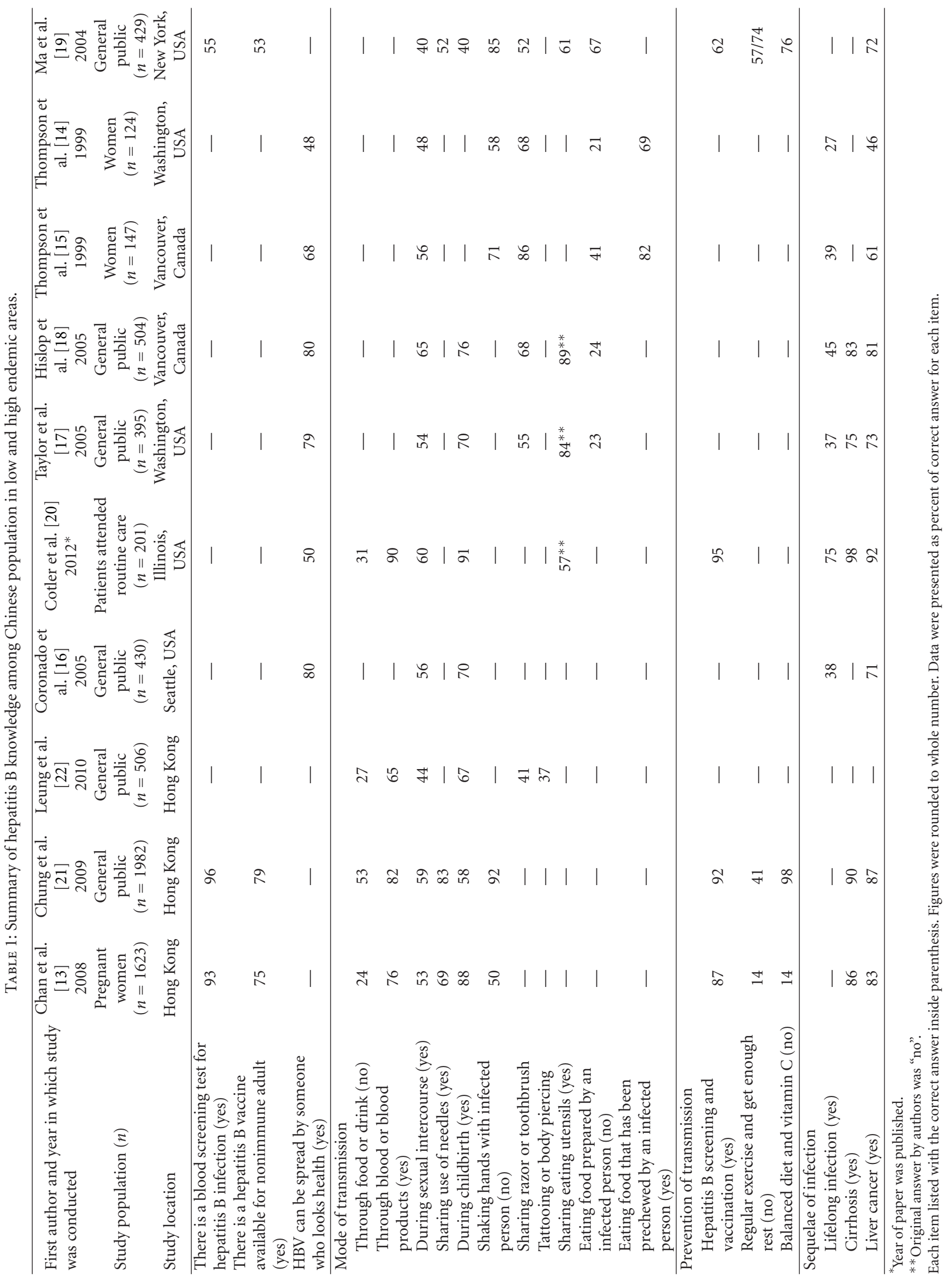


contact with infected urine was an unlikely or remote cause of infection among the fertile women in our society, contact with saliva, such as from kissing and even from orally sexual activity, is probably much more common. Further studies are warranted to clarify the role of horizontal transmission by infected saliva, but in the meantime, it would be prudent to remind the community not to share eating utensils and to avoid all the aforementioned practices in the family setting for hygiene considerations.

On the other hand, in line with other researchers, we have also found erroneous knowledge amongst our subjects. In our study, only $24 \%$ of the subjects recognized that $\mathrm{HBV}$ is not transmitted by the oral-fecal route, which was consistent with the findings of other studies in the same area [21, 22]. This suggested that there was confusion between hepatitis A and hepatitis B amongst the general public.

4.2. Prevention. Only a few studies had examined the knowledge on prevention of HBV transmission, and the majority of the respondents knew that $\mathrm{HBV}$ transmission could be prevented by hepatitis B screening and vaccination (6295\%). In Hong Kong, vaccination programmes are provided to all nonimmune adults who requested vaccination by institutions such as universities, and nongovernment organizations such as the Family Planning Association, and by general practitioners $[5,56]$. With increased public awareness of HBV infection over the past two decades, the rate of $\mathrm{HBV}$ vaccination uptake at their own expense amongst the pregnant women in Hong Kong increased from $13 \%$ in 1996 [5] to $33 \%$ in 2008 [56]. Nevertheless, there is much room for improvement and catch-up vaccination or booster doses should be offered to all individuals without confirmed immunity to HBV whenever such individuals are identified.

Among the public, less is known about the risk and importance of horizontal transmission; although health education pamphlets, posters, and television advertisements have explained about the risk of HBV in needle-sharing, acupuncture and tattooing, it is not certain to what extent do the general and obstetric population realizes the importance of such information. In Hong Kong, safe injection practice is performed in the clinical settings without the reuse of syringes and needles in both public and private hospitals, and our pregnant women are at minimal risk of HBV infection via routine antenatal blood taking or drug injection. However, acupuncture and beauty treatments were risk factors in the spread of HBV infection [57, 58], but the safe use of needles in acupuncture and beauty treatments cannot be guaranteed, even though disposable needles are available. In Mainland China, the injection practice, especially in some rural areas, remains questionable. The difference in rate of HBV infection between our local women and the immigrants from Mainland China could be partly explained on the differences in these practices, but this issue needs to be explored in further studies.

At the same time, there remains a substantial portion of our subjects with erroneous knowledge on the prevention of HBV transmission, as only $14 \%$ of pregnant respondents

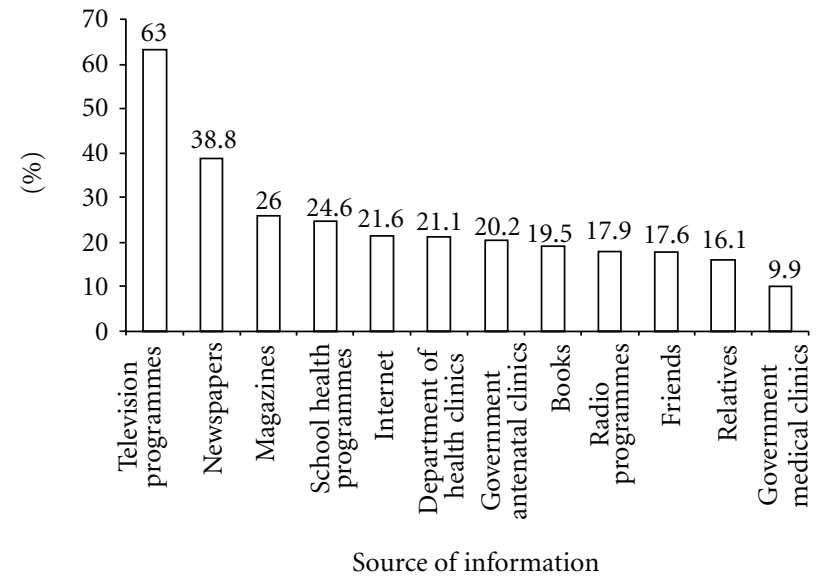

FIgURE 1: The distribution of the source of information on HBV knowledge.

knew that neither a balanced diet and vitamin C consumption, nor regular exercise, nor getting enough rest can prevent $\mathrm{HBV}$ infection. However, in another recent study amongst the general public, up to $98 \%$ of the respondents knew that balanced diet and vitamin $\mathrm{C}$ could not prevent $\mathrm{HBV}$ infection [21]. Such discrepancy of knowledge found in the same area could be explained by the fact that subjects from the study of Chung et al. [21] were generally better educated, while the pregnant women attending our antenatal clinic were deficient in the knowledge about prevention of $\mathrm{HBV}$ infection.

\section{Factors Influencing Knowledge among the Fertile Women}

5.1. Immigration. In some low endemicity countries such as the United States and Canada, immigration from highly endemic areas such as Southeast Asia has been the major contributor to the horizontal transmission from the carriers to other susceptible individuals, leading to an increasing prevalence of chronic HBV infection [16]. In Hong Kong, a high influx rate of immigrants and visitors from Mainland China in the past decade is thought to be an important contributing factor to the persistence of a high prevalence rate of chronic infection in pregnant women. We had demonstrated an association between status of residency and the HBV carriage rate $5.7 \%$ for locally born residents versus $14.2 \%$ for immigrants and nonresidents), with the uptake of hepatitis B vaccine (36.0\% for local residents versus $22.3 \%$ for nonlocal residents), and poor knowledge on $\mathrm{HBV}$ transmission and prevention (aOR ranged 1.63-2.01 for new immigrants and 1.65-1.81 for nonresidents as compared with locally born residents) $[12,13,56]$.

5.2. Sources of Information. In Hong Kong, the Viral Hepatitis Preventive Service has been launched by the Department of Health in Hong Kong in July 1998, conducting epidemiological surveillance and distributing information through various channels to the general public. There are also other 


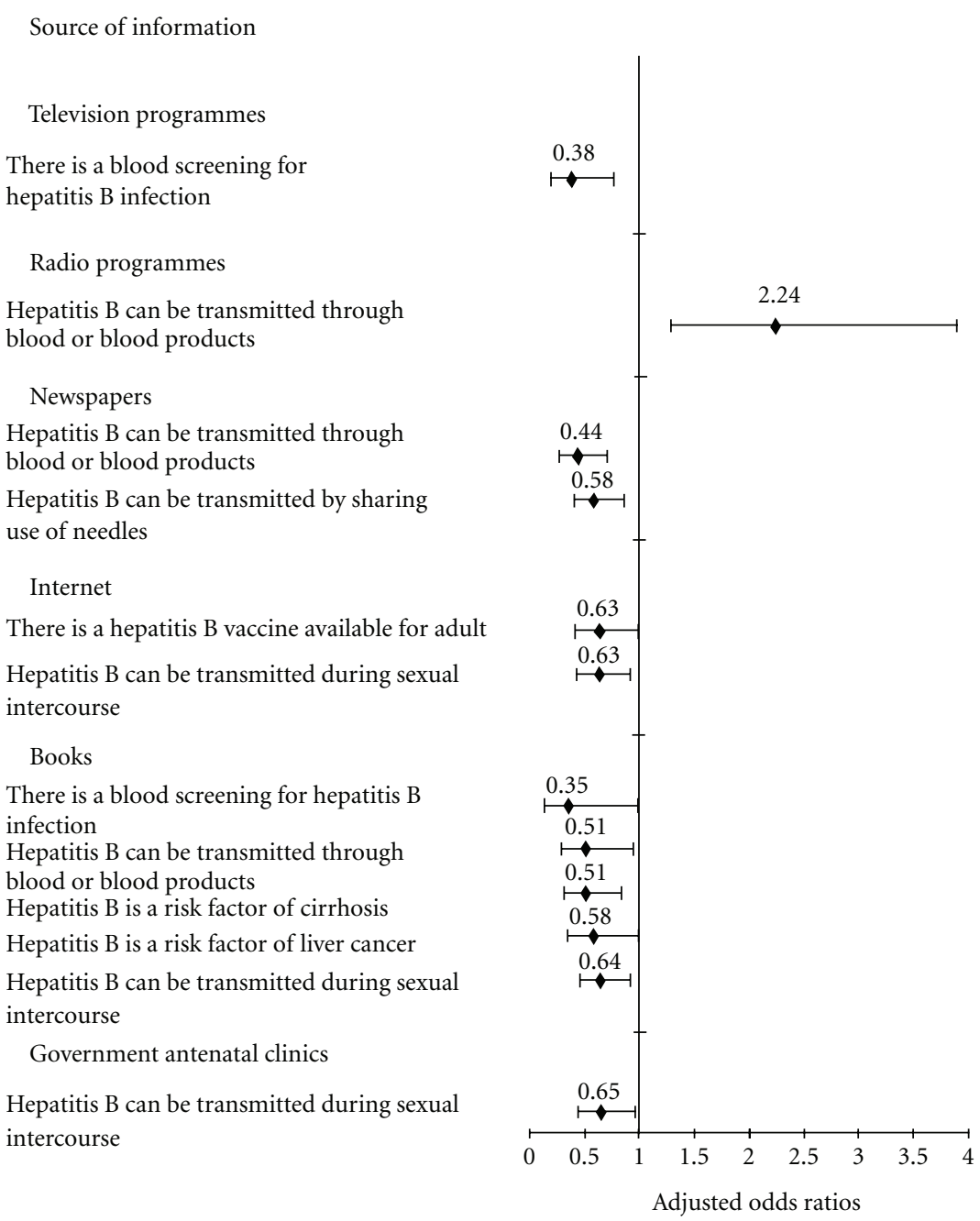

FIgURE 2: The adjusted odds ratios and 95\% CI of the source of information for incorrect responses to items.

local sources or channels available for the dissemination of information regarding HBV infection in Hong Kong, such as healthcare professionals, mass media, the Department of Health website [59], and educational pamphlets. In our community, the mass media are the most preferred channels for disseminating educational materials and information to general public at the community level, because of their popularity $[60,61]$. Mass media, such as televisions and radios, are available to almost every household in Hong Kong, and free news channels are available in public transports such as buses and the mass transit system. Furthermore, many newspapers are distributed free of charge and internet services are also easily accessible in the community. We have therefore examined the sources of information on HBV infection and the roles of various channels in the dissemination of information with respect to the level of knowledge [13], which was not addressed in previous studies. Our aim was to determine whether accessibility and utilization of the various sources of information could have contributed to deficient or incorrect knowledge among our respondents.

We found that mass media is the most important source of hepatitis B knowledge among our pregnant women, with the two leading sources of knowledge being television programmes $(63.0 \%)$ and newspapers (38.8\%) (Figure 1). Similar to television programmes, radio programmes are also one of the most rapid means of disseminating information in real time to the public and of increasing their awareness and knowledge of HBV infection, but only a minority (17.9\%) indicated that radio programmes were useful in learning about HBV infection. Each of the other sources accounted for $26 \%$ or less. Medical and health care services were among the lowest with the poorest source being government medical clinics $(9.9 \%)$. What was most disappointing was that around $80 \%$ of the respondents did not receive any information about HBV infection from the medical and healthcare services or medical professionals, which should have been the optimal channel to disseminate correct medical information. In Hong Kong, primary medical care is provided at a nominal charge to all local residents, and many charitable organizations provide free medical care to those who cannot afford the outpatient charges. Furthermore, government maternal and child health centers and the Family Planning Association also provide service to all without restriction. The mechanisms of this failure remain to be 
established, but it was possible that when these women sought help from such services, they were focused only on their complaints or problems at the time. As well, the need for specific health education on the common endemic infections in our territory, such as HBV infection, might not have crossed the minds of the health care professionals at the time due to the assumption that such as information should have been readily available.

As we have noted that incorrect or misleading messages have been provided to our subjects, the effects of the various channels of dissemination of the information on HBV infection were assessed by multivariate logistic analysis and the adjusted odds ratios of the source of information for incorrect response on individual item were presented in Figure 2. After adjusting for the significant sociodemographic, medical, and obstetric factors found in univariate analysis [13], television programmes (aOR 0.38 in 1 item), books (aOR range $0.35-0.64$ in 5 items), newspapers (aOR range 0.44 and 0.58 in 2 items), internet (both aORs 0.63 for 2 items), and government antenatal clinics (aOR 0.65 for 1 item) were associated with reduced provision of incorrect knowledge about HBV infection for most items. At the same time, however, radio programmes (aOR 2.24) were also revealed to be the significant source of provision of incorrect information regarding the transmission of $\mathrm{HBV}$ through blood or other blood products. We suspect that some of information acquired from this channel might be erroneous or lacking a scientific or medical basis, and this issue should be examined specifically in future studies.

\section{Conclusion}

Numerous studies on HBV infection, its sequelae, and the various means of prevention have been published in the past three decades. Yet even the latest studies have found areas of deficient or even erroneous knowledge on HBV infection, and we are especially disappointed to learn from the findings in our pregnant women that there is much room for improvement in the provision of appropriate and correct information on $\mathrm{HBV}$ transmission and prevention to the public. We suspect that deficient knowledge and misconceptions, especially regarding the various means of horizontal transmission, have probably contributed to the persistently high prevalence of HBV infection in our obstetric population. Social stigma can result from poor knowledge on HBV infection, as is the case in Mainland China. In China, HBV carriers face social discrimination affecting both their life and work as many employers and universities refuse to accept those who were tested positive from the preemployment and preenrolment medical checkup, although according to Ministry of Health of the People's Republic of China, the China Government has decided to legislate against the hepatitis B discrimination recently [62]. On the other hand, appropriate public education could reduce the stigma attached to HBV carriers, as shown in the United States that higher levels of knowledge regarding HBV were associated with lower degrees of stigma [20]. Where resources are limited, targeting women in the reproduction age group for health education would be most cost-effective due to their roles as mothers and care providers to the entire household, so that their possession of correct knowledge on HBV transmission and infection would have the greatest overall impact on the population. More studies on the control of HBV infection through enhanced public health education programmes as an adjunct to any ongoing immunization programme in endemic areas are warranted.

\section{References}

[1] World Health Organization, "Hepatitis B," Fact Sheet No. 204, World Health Organization, Geneva, Switzerland, 2000, http://www.who.int/mediacentre/factsheets/fs204/en/index .html.

[2] R. P. Beasley, L. Y. Hwang, C. C. Lin, and C. S. Chien, "Hepatocellular carcinoma and hepatitis B virus. A prospective study of 22707 men in Taiwan," The Lancet, vol. 2, no. 8256, pp. 1129-1133, 1981.

[3] R. P. Beasley, "Hepatitis B virus as the etiologic agent in hepatocellular carcinoma-epidemiologic considerations," Hepatology, vol. 2, supplement 2, pp. 21S-26S, 1982.

[4] R. P. Beasley, "Hepatitis B virus. The major etiology of hepatocellular carcinoma," Cancer, vol. 61, no. 10, pp. 1942-1956, 1988.

[5] L. C. Kwan, Y. Y. Ho, and S. S. Lee, "The declining HBsAg carriage rate in pregnant women in Hong Kong," Epidemiology and Infection, vol. 119, no. 2, pp. 281-283, 1997.

[6] Department of Health, Hong Kong, Surveillance of viral hepatitis in Hong Kong-2006 update report, http://www.info .gov.hk/hepatitis/doc/hepsurv06.pdf.

[7] C. Y. Chan, S. D. Lee, and K. J. Lo, "Legend of hepatitis B vaccination: the Taiwan experience," Journal of Gastroenterology and Hepatology, vol. 19, no. 2, pp. 121-126, 2004.

[8] M. H. Chang, C. J. Chen, M. S. Lai et al., "Universal hepatitis $B$ vaccination in Taiwan and the incidence of hepatocellular carcinoma in children," The New England Journal of Medicine, vol. 336, no. 26, pp. 1855-1859, 1997.

[9] A. K. Y. Lee, H. M. H. Ip, and V. C. W. Wong, "Mechanisms of maternal-fetal transmission of hepatitis B virus," Journal of Infectious Diseases, vol. 138, no. 5, pp. 668-671, 1978.

[10] V. C. W. Wong, H. M. H. Ip, H. W. Reesink et al., "Prevention of the HBsAg carrier state in newborn infants of mothers who are chronic carriers of HBsAg and HBeAg by administration of hepatitis B vaccine and hepatitis B immunoglobulin. Doubleblind randomised placebo-controlled study," The Lancet, vol. 1, no. 8383, pp. 921-926, 1984.

[11] S. S. H. Suen, T. T. Lao, D. S. Sahota, T. K. Lau, and T. Y. Leung, "Implications of the relationship between maternal age and parity with hepatitis B carrier status in a high endemicity area," Journal of Viral Hepatitis, vol. 17, no. 5, pp. 372-378, 2010.

[12] O. K. Chan, T. T. Lao, S. S. H. Suen, T. K. Lau, and T. Y. Leung, "Correlation between maternal hepatitis B surface antigen carrier status with social, medical and family factors in an endemic area: have we overlooked something?" Infection, vol. 39, no. 5, pp. 419-426, 2011.

[13] O. K. Chan, T. T. Lao, S. S. H. Suen, T. K. Lau, and T. Y. Leung, "Knowledge on hepatitis B infection among pregnant women in a high endemicity area," Patient Education and Counseling, vol. 85, no. 3, pp. 516-520, 2010.

[14] M. J. Thompson, V. M. Taylor, J. C. Jackson et al., "Hepatitis B knowledge and practices among Chinese American women in 
Seattle, Washington," Journal of Cancer Education, vol. 17, no. 4, pp. 222-226, 2002.

[15] M. J. Thompson, V. M. Taylor, Y. Yasui et al., "Hepatitis B knowledge and practices among Chinese Canadian Women in Vancouver, British Columbia," Canadian Journal of Public Health, vol. 94, no. 4, pp. 281-286, 2003.

[16] G. D. Coronado, V. M. Taylor, S. P. Tu et al., "Correlates of hepatitis B testing among Chinese Americans," Journal of Community Health, vol. 32, no. 6, pp. 379-390, 2007.

[17] V. M. Taylor, S. P. Tu, E. Woodall et al., "Hepatitis B knowledge and practices among Chinese immigrants to the United States," Asian Pacific Journal of Cancer Prevention, vol. 7, no. 2, pp. 313-317, 2006.

[18] T. G. Hislop, C. Teh, A. Low et al., "Hepatitis B knowledge, testing and vaccination levels in Chinese immigrants to British Columbia, Canada," Canadian Journal of Public Health, vol. 98, no. 2, pp. 125-129, 2007.

[19] G. X. Ma, S. E. Shive, J. I. Toubbeh, Y. Tan, and D. Wu, "Knowledge, attitudes, and behaviors of Chinese hepatitis B screening and vaccination," American Journal of Health Behavior, vol. 32, no. 2, pp. 178-187, 2008.

[20] S. J. Cotler, S. Cotler, H. Xie, B. J. Luc, T. J. Layden, and S. S. Wong, "Characterizing hepatitis B stigma in Chinese immigrants," Journal of Viral Hepatitis, vol. 19, no. 2, pp. 147-152, 2012.

[21] P. W. Chung, S. H. Suen, O. K. Chan, T. H. Lao, and T. Y. Leung, "Awareness and knowledge of hepatitis B infection and prevention and the use of hepatitis B vaccination in the Hong Kong adult Chinese population," Chinese Medical Journal, vol. 125, no. 3, pp. 422-427, 2012.

[22] C. M. Leung, W. H. Wong, K. H. Chan et al., "Public awareness of hepatitis B infection: a population-based telephone survey in Hong Kong," Hong Kong Medical Journal, vol. 16, no. 6, pp. 463-469, 2010.

[23] J. L. Yao, "Perinatal transmission of hepatitis B virus infection and vaccination in China," Gut, vol. 38, supplement 2, pp. S37-S38, 1996.

[24] J. Hou, Z. Liu, and F. Gu, "Epidemiology and prevention of hepatitis B virus infection," International Journal of Medical Sciences, vol. 2, no. 1, pp. 50-57, 2005.

[25] Y. Poovorawan, S. Sanpavat, W. Pongpunlert, S. Chumdermpadetsuk, P. Sentrakul, and A. Safary, "Protective efficacy of a recombinant DNA hepatitis B vaccine in neonates of $\mathrm{HBe}$ antigen-positive mothers," The Journal of the American Medical Association, vol. 261, no. 22, pp. 3278-3281, 1989.

[26] C. Y. Lee, L. M. Huang, M. H. Chang et al., "The protective efficacy of recombinant hepatitis B vaccine in newborn infants of hepatitis B e antigen-positive-hepatitis B surface antigen carrier mothers," Pediatric Infectious Disease Journal, vol. 10, no. 4, pp. 299-303, 1991.

[27] R. P. Beasley, L. Y. Hwang, C. C. Lin et al., "Hepatitis B immune globulin (HBIG) efficacy in the interruption of perinatal transmission of hepatitis B virus carrier state. Initial report of a randomised double-blind placebo-controlled trial," The Lancet, vol. 2, no. 8243, pp. 388-393, 1981.

[28] E. K. Yeoh, "Hepatitis B vaccination-who should be vaccinated?" Journal of the Hong Kong Medical Association, vol. 39, pp. 208-209, 1987.

[29] P. I. Lee, C. Y. Lee, L. M. Huang, J. M. Chen, and M. H. Chang, "A follow-up study of combined vaccination with plasmaderived and recombinant hepatitis B vaccines in infants," Vaccine, vol. 13, no. 17, pp. 1685-1689, 1995.

[30] R. P. Beasley, L. Y. Hwang, C. E. Stevens et al., "Efficacy of hepatitis B immune globulin for prevention of perinatal transmission of the hepatitis B virus carrier state: final report of a randomized double-blind, placebo-controlled trial," Hepatology, vol. 3, no. 2, pp. 135-141, 1983.

[31] A. S. F. Lok, "Hepatitis B vaccination in Hong Kong," Journal of Gastroenterology and Hepatology, vol. 8, supplement 1, pp. S27-S29, 1993.

[32] H. Obata, N. Hayashi, Y. Motoike et al., "A prospective study on the development of hepatocellular carcinoma from liver cirrhosis with persistent hepatitis B virus infection," International Journal of Cancer, vol. 25, no. 6, pp. 741-747, 1980.

[33] K. C. Hyams, "Risks of chronicity following acute hepatitis B virus infection: a review," Clinical Infectious Diseases, vol. 20, no. 4, pp. 992-1000, 1995.

[34] M. J. Alter and H. S. Margolis, "The emergence of hepatitis B as a sexually transmitted disease," Medical Clinics of North America, vol. 74, no. 6, pp. 1529-1541, 1990.

[35] L. Simonsen, A. Kane, J. Lloyd, M. Zaffran, and M. Kane, "Unsafe injections in the developing world and transmission of bloodborne pathogens: a review," Bulletin of the World Health Organization, vol. 77, no. 10, pp. 789-800, 1999.

[36] A. Kane, J. Lloyd, M. Zaffran, L. Simonsen, and M. Kane, "Transmission of hepatitis B, hepatitis C and human immunodeficiency viruses through unsafe injections in the developing world: model-based regional estimates," Bulletin of the World Health Organization, vol. 77, no. 10, pp. 801-807, 1999.

[37] J. T. Dongdem, S. Kampo, I. N. Soyiri, P. N. Asebga, J. B. Ziem, and K. Sagoe, "Prevalence of hepatitis B virus infection among blood donors at the Tamale Teaching Hospital, Ghana (2009)," BMC Research Notes, vol. 5, no. 1, article 115, 2012.

[38] J. Heathcote, C. H. Cameron, and D. S. Dane, "Hepatitis B antigen in saliva and semen," The Lancet, vol. 1, no. 7847, pp. 71-73, 1974.

[39] G. R. Irwin, A. M. Allen, W. H. Bancroft et al., "Hepatitis B antigen in saliva, urine, and stool," Infection and Immunity, vol. 11, no. 1, pp. 142-145, 1975.

[40] S. V. Feinman, O. Krassnitski, J. C. Sinclair, D. M. Wrobel, and B. Berris, "Hepatitis B surface antigen in saliva of $\mathrm{HB}(\mathrm{s}) \mathrm{Ag}$ carriers," Journal of Laboratory and Clinical Medicine, vol. 85, no. 6, pp. 1042-1048, 1975.

[41] H. Ben-Aryeh, I. Ur, and E. Ben-Porath, "The relationship between antigenaemia and excretion of hepatitis B surface antigen in human whole saliva and in gingival crevicular fluid," Archives of Oral Biology, vol. 30, no. 1, pp. 97-99, 1985.

[42] S. J. Cunningham, R. Cunningham, M. G. A. Izmeth, B. Baker, and C. A. Hart, "Seroprevalence of hepatitis B and C in a Merseyside hospital for the mentally handicapped," Epidemiology and Infection, vol. 112, no. 1, pp. 195-200, 1994.

[43] A. A. van der Eijk, H. G. M. Niesters, H. M. Götz et al., "Paired measurements of quantitative hepatitis B virus DNA in saliva and serum of chronic hepatitis B patients: implications for saliva as infectious agent," Journal of Clinical Virology, vol. 29, no. 2, pp. 92-94, 2004.

[44] K. Kidd-Ljunggren, A. Holmberg, J. Bläckberg, and B. Lindqvist, "High levels of hepatitis B virus DNA in body fluids from chronic carriers," Journal of Hospital Infection, vol. 64, no. 4, pp. 352-357, 2006.

[45] I. L. Heiberg, M. Hoegh, S. Ladelund, H. G. M. Niesters, and B. Hogh, "Hepatitis B virus dna in saliva from children with chronic hepatitis B infection: implications for saliva as a potential mode of horizontal transmission," Pediatric Infectious Disease Journal, vol. 29, no. 5, pp. 465-467, 2010.

[46] A. Y. Hui, L. C. T. Hung, P. C. H. Tse, W. K. Leung, P. K. S. Chan, and H. L. Y. Chan, "Transmission of hepatitis B by 
human bite-confirmation by detection of virus in saliva and full genome sequencing," Journal of Clinical Virology, vol. 33, no. 3, pp. 254-256, 2005.

[47] R. M. Scott, R. Snitbhan, W. H. Bancroft, H. J. Alter, and M. Tingpalapong, "Experimental transmission of hepatitis B virus by semen and saliva," Journal of Infectious Diseases, vol. 142, no. 1, pp. 67-71, 1980.

[48] T. P. Cancio Bello, M. de Medina, J. Shorey, M. D. Valledor, and E. R. Schiff, "An institutional outbreak of hepatitis B related to a human biting carrier," Journal of Infectious Diseases, vol. 146, no. 5, pp. 652-656, 1982.

[49] C. Stornello, "Transmission of hepatitis B via human bite," The Lancet, vol. 338, no. 8773, pp. 1024-1025, 1991.

[50] I. J. B. Spijkerman, L. J. van Doorn, M. H. W. Janssen et al., "Transmission of hepatitis B virus from a surgeon to his patients during high-risk and low-risk surgical procedures during 4 years," Infection Control and Hospital Epidemiology, vol. 23, no. 6, pp. 306-312, 2002.

[51] C. Lobato, J. Tavares-Neto, M. Rios-Leite et al., "Intrafamilial prevalence of hepatitis B virus in Western Brazilian Amazon region: epidemiologic and biomolecular study," Journal of Gastroenterology and Hepatology, vol. 21, no. 5, pp. 863-868, 2006.

[52] N. J. Petersen, D. H. Barrett, W. W. Bond et al., "Hepatitis $\mathrm{B}$ surface antigen in saliva, impetiginous lesions, and the environment in 2 remote Alaskan villages," Applied and Environmental Microbiology, vol. 32, no. 4, pp. 572-574, 1976.

[53] W. W. Bond, M. S. Favero, N. J. Petersen, C. R. Gravelle, J. W. Ebert, and J. E. Maynard, "Survival of hepatitis B virus after drying and storage for one week," The Lancet, vol. 1, no. 8219, pp. 550-551, 1981.

[54] R. Zachoval, G. Frösner, F. Deinhardt, and D. Höss, "Persistence of hepatitis B virus antigens in dried blood," The Lancet, vol. 1 , no. 8223, article $778,1981$.

[55] K. T. Goh, J. L. Ding, E. H. Monteiro, and C. J. Oon, "Hepatitis B infection in households of acute cases," Journal of Epidemiology and Community Health, vol. 39, no. 2, pp. 123-128, 1985.

[56] O. K. Chan, S. S. H. Suen, T. T. H. Lao, V. K. T. Leung, S. W. Yeung, and T. Y. Leung, "Determinants of hepatitis B vaccine uptake among pregnant Chinese women in Hong Kong," International Journal of Gynecology and Obstetrics, vol. 106, no. 3, pp. 232-235, 2009.

[57] A. Mele, R. Corona, M. E. Tosti et al., "Beauty treatments and risk of parenterally transmitted hepatitis: results from the hepatitis surveillance system in Italy," Scandinavian Journal of Infectious Diseases, vol. 27, no. 5, pp. 441-444, 1995.

[58] A. Mariano, A. Mele, M. E. Tosti et al., "Role of beauty treatment in the spread of parenterally transmitted hepatitis viruses in Italy," Journal of Medical Virology, vol. 74, no. 2, pp. 216-220, 2004.

[59] Department of Health, Viral Hepatitis Preventive Service, http://www.info.gov.hk/hepatitis.

[60] C. Davis, M. B. Noel, S. F. F. Chan, and L. S. Wing, "Knowledge, attitudes and behaviours related to HIV and AIDS among Chinese adolescents in Hong Kong," Journal of Adolescence, vol. 21, no. 6, pp. 657-665, 1998.

[61] C. S. Chu, T. W. Chan, H. M. Hui, L. P. Samaranayake, J. C. Chan, and S. H. Wei, "The knowledge and attitude of Hong Kong secondary school teachers and students towards HIV infection and dentistry," Community Dental Health, vol. 12, no. 2, pp. 110-114, 1995.

[62] Ministry of Health of the People's Republic of China, 2009, http://medicine.people.com.cn/GB/135894/178335/index .html. 


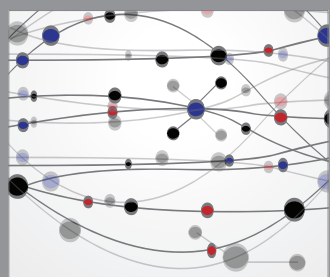

The Scientific World Journal
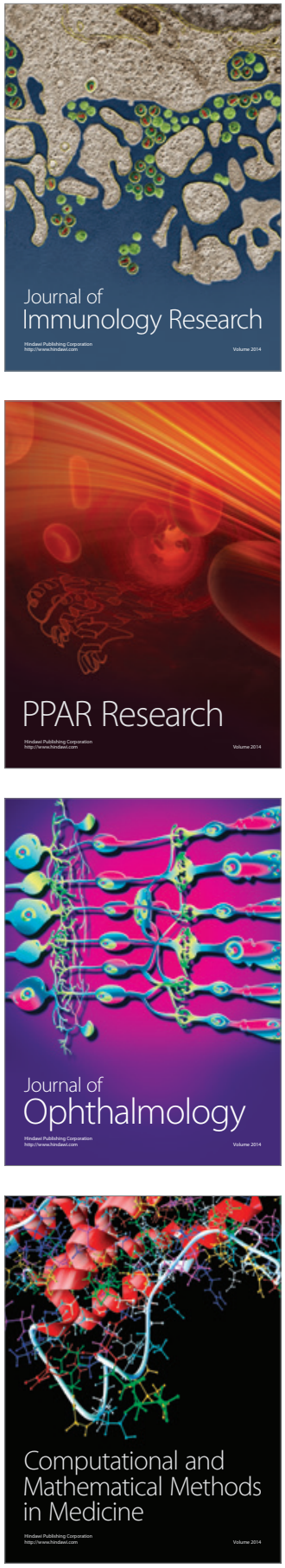

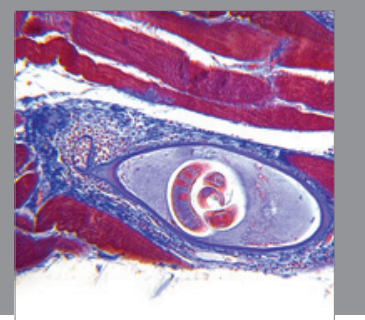

Gastroenterology

Research and Practice
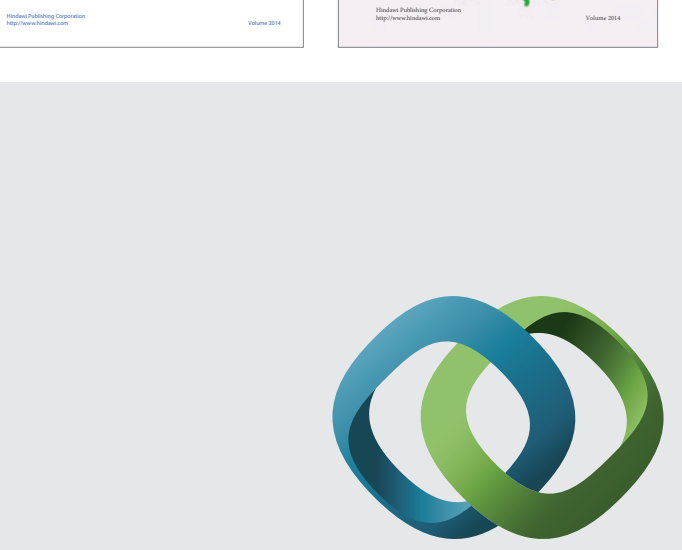

\section{Hindawi}

Submit your manuscripts at

http://www.hindawi.com
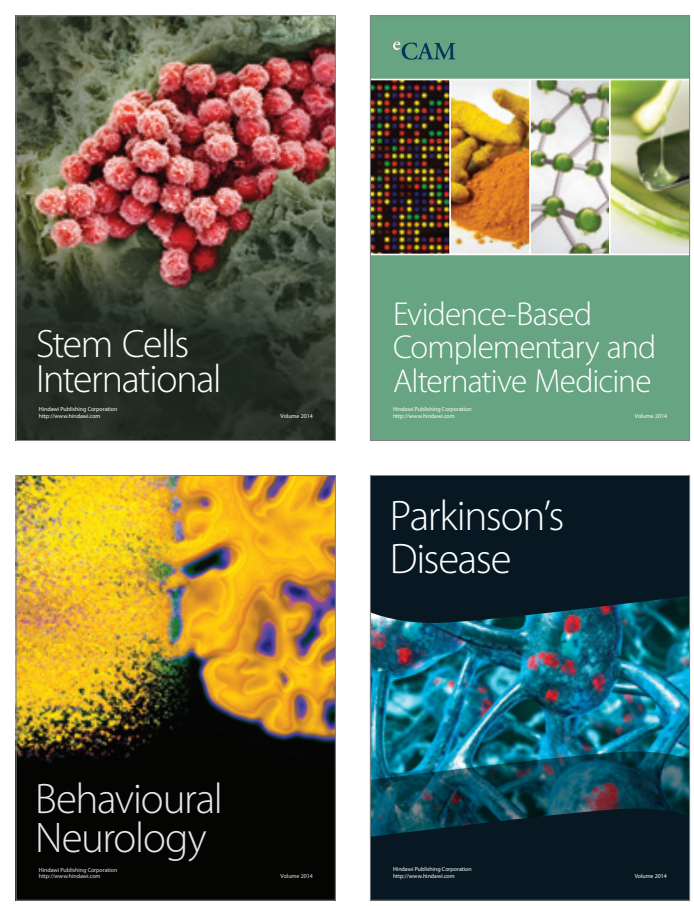

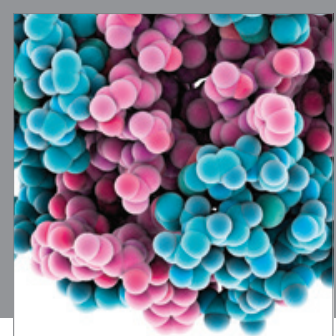

Journal of
Diabetes Research

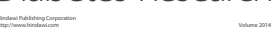

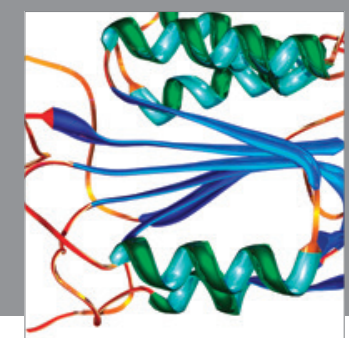

Disease Markers
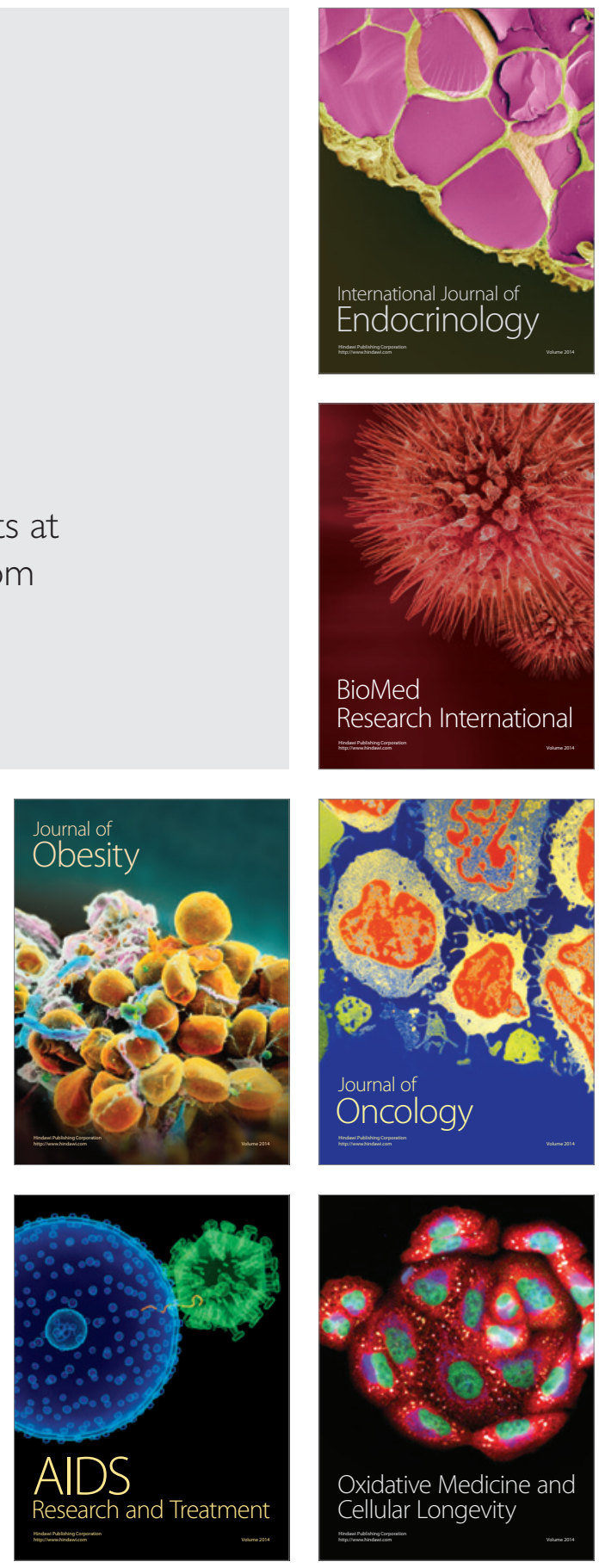